\title{
Una propuesta metodológica para el análisis del paisaje cultural urbano en Zacatecas ${ }^{1}$
}

\author{
A method for analysing the urban cultural landscape of Zacatecas
}

\author{
María Inés Ortiz Álvarez ${ }^{2}$ \\ Luz María Oralia Tamayo Pérez ${ }^{3}$ \\ Alma Villaseñor Franco ${ }^{4}$
}

\section{Resumen}

En este trabajo se proponen los elementos significativos que permiten el análisis del paisaje cultural urbano de las ciudades patrimoniales, tomando como base las propuestas establecidas por la Organización de las Naciones Unidas para la Educación, la Ciencia y la Cultura (UNESCO), concretamente para la ciudad de Zacatecas. El énfasis se hace en los valores tanto naturales como culturales que le dan a las ciudades patrimoniales un carácter significativo por su singularidad. En el análisis y en la valoración de la ciudad se integra el paisaje natural que la circunda, pues se considera parte de su espacio patrimonial, e igualmente se resalta la importancia de señalar cuando este se encuentre amenazado, ya sea por el crecimiento poblacional o por otras causas.

Palabras clave: paisaje cultural urbano, propuesta metodológica.

1 Este artículo hace parte del proyecto: "Los paisajes culturales en México. Su valor patrimonial en la geografía", del Grupo de investigación Paisajes Culturales, Instituto de Geografía. Financiación: Dirección General de Asuntos del Personal Académico, Programa de Investigación e Innovación Tecnológica IN300412, Universidad Nacional Autónoma de México.

2 Doctora en Geografía, Universidad Nacional Autónoma de México. Instituto de Geografía investigador titular B, tiempo completo definitivo, Departamento de Geografía Social, Universidad Nacional Autónoma de México, México, mioa@unam.mx

3 Doctora en Geografía, Universidad Nacional Autónoma de México. Instituto de Geografía investigador asociado C, tiempo completo definitivo, Departamento de Geografía Social, Universidad Nacional Autónoma de México. México, ptamayo@unam.mx

4 Doctora en Geografía, Universidad Nacional Autónoma de México. Profesora investigadora titular C, tiempo completo, Unidad Académica de Ingeniería, Universidad Autónoma de Guerrero. México, alvif27@gmail.com 


\section{Abstract}

We propose key criteria that allow analysis of the urban cultural landscape of heritage cities; they are based on the proposals set out by the United Nations Educational, Scientific and Cultural Organization (UNESCO). To illustrate the use of these criteria is taken Zacatecas. Emphasis is placed on the natural and cultural values whose uniqueness gives each heritage city its own character. Included in the analysis and evaluation is the natural landscape that surrounds it and that is considered part of its heritage; it is important to identify when this landscape is threatened by population growth or other factors.

Keywords: urban cultural landscape, proposed methodology. 


\section{Introducción}

En México se han hecho esfuerzos por rescatar algunos sitios declarados como Patrimonio de la Humanidad. En el actual Plan Nacional de Desarrollo 2007-2012, del que deriva el Programa Nacional de Cultura para el mismo período, se definen varias estrategias dirigidas a la preservación de espacios de cultura y arte, entre las cuales están las “... inversiones en la infraestructura cultural destinadas a programas de mantenimiento y renovación de los espacios y servicios que ahora funcionan", para satisfacer la demanda de las comunidades que han visto deteriorarse las instalaciones culturales de que disponen. Sin embargo, hace falta más trabajo al respecto, ya que México posee numerosos espacios cuyos valores estético natural, cultural, histórico e identitario, no se han resaltado y, al no estimar esos elementos potencialmente paisajísticos, se descuidan y deterioran, además, con el paso del tiempo, se pierden, afectando el patrimonio comunitario.

Es necesario contar con una metodología que permita analizar y evaluar sistemáticamente los componentes de un paisaje cultural urbano determinado. En el Instituto de Geografía de la Universidad Nacional Autónoma de México, se han analizado algunas ciudades mexicanas, con el fin de encontrar elementos paisajísticos que puedan ser considerados patrimoniales.

En este trabajo se presenta una propuesta metodológica que permite sistematizar el análisis de los elementos que deben considerarse para el rescate y la conservación de un paisaje cultural urbano, teniendo en cuenta su belleza y singularidad, y señalando los fundamentos para dicha valoración, a fin de ser agregado en la lista de lugares que ya han sido considerados zonas patrimoniales. Hipotéticamente se parte de la premisa de que si se cuenta con un instrumento metodológico que permita evaluar el paisaje cultural de una ciudad, se tendrán mejores bases para su inclusión en la lista mencionada o para su conservación, según sea el proceso. Se selecciona como caso de estudio el centro histórico de la ciudad de Zacatecas que, si bien fue declarado Patrimonio Cultural de la Humanidad a partir de 1993 -designación apoyada en la riqueza arquitectónica, cultural e histórica que posee-, no se tomó en cuenta el paisaje natural que la circunda y que forma parte importante de su paisaje cultural.

Es importante señalar que este trabajo surge por la necesidad de diseñar herramientas para el análisis del paisaje cultural urbano de las zonas patrimoniales mexicanas, y toma como fundamentación teórica la se- 
ñalada por la misma UNESCO para poner en valor los sitios, por tanto, este artículo tiene por objeto proponer una metodología para el análisis de dichos sitios, considerando hipotéticamente que si se tiene una herramienta metodológica adecuada, se podrán analizar y fundamentar adecuadamente los paisajes culturales urbanos de México. El tema se ha trabajado desde hace tiempo por las autoras, gracias a un proyecto auspiciado por la Dirección General de Asuntos del Personal Académico (DGAPA), mediante el Programa de Apoyo a Proyectos de Investigación e Innovación Tecnológica (PAPIIT) de la Universidad Nacional Autónoma de México.

\section{Las acciones internacionales y el patrimonio mundial}

Se han realizado varias acciones tendientes a la conservación de la herencia cultural, como ejemplo se pueden citar la Carta Europea de 1975 sobre la Conservación Integrada del Patrimonio Arquitectónico, la Convención del Patrimonio Mundial de 1972, la Declaración y Resoluciones de la Conferencia de Helsinki de 1996 y el Convenio Europeo del Paisaje de 2000, por citar algunas de las más divulgadas en torno al tema. El objetivo principal de dichas acciones es proteger y preservar algunos sitios que por su valor estético o cultural deben conservarse, porque constituyen una herencia valiosa para las generaciones presentes y futuras. Estos sitios son una fuente de riqueza que podría generar y fomentar ingresos por servicios turísticos.

En México se tienen ya determinados sitios declarados Patrimonio de la Humanidad, entre los últimos nominados, como se recordará, está el campus central de Ciudad Universitaria de la Universidad Nacional Autónoma de México, el 28 de junio de 2007.

\section{Consideraciones teóricas}

El análisis y conocimiento de esos paisajes humanizados permite, por una parte, descubrir y ratificar los valores inherentes a la población que los ha conformado, relacionados con su identidad, tradiciones y sentimiento de pertenencia a ese espacio comunitario, y, por otra, crear conciencia en la misma población sobre la importancia de resguardarlos y preservar el espacio geográfico en el que se asientan los valores culturales que les han dado origen. Elementos que pueden hacer posible su conservación, su aprovechamiento turístico y su transmisión cultural a las generaciones futuras.

El valor de estos espacios se da a través de la revelación de las múl- 
tiples relaciones entre el hombre y el medio; es decir, la interacción del paisaje natural con la colectividad y las transformaciones que esta le ha impreso. El estudio geográfico, que se enfocaba inicialmente al paisaje natural, en decenios recientes ha registrado una reorientación con énfasis creciente sobre el hombre. La ciudad, desde el punto de vista de la geografía cultural, es vista como la creación interna de una cultura, la cual se ha visto trastocada por la urbanización masiva que provoca procesos contrapuestos de desocupación de ciertos lugares y de excesiva presión demográfica sobre otros ${ }^{5}$.

Los casos por estudiar son paisajes culturales documentados por la literatura y recogidos a través de la imagen, la pintura, el grabado o la fotografía e, incluso, el cine y la músi$\mathrm{ca}^{6}$, paisajes que ahora se encuentran amenazados por los procesos más recientes de urbanización y de cambio económico y social que acompañan a la globalización.

El concepto de paisaje que se em-

5 Por ejemplo, la población que ocupa o invade terrenos restringidos, que pone en peligro la conservación de monumentos y edificios de valor singular y de paisajes irrepetibles, consecuencia de modos de vida y estructuras económicas, sociales y políticas que se han sucedido a lo largo del tiempo.

6 Como es el caso de canciones que describen el paisaje, las tradiciones o los sentimientos de nostalgia por un lugar, ejemplos: Veracruz, Guadalajara, Janitzio, Chapala, la Canción Mixteca o la Marcha Aréchiga, mejor conocida como Marcha Zacatecas, cuyo autor fue Genaro Codina, por mencionar solo algunas. plea en este trabajo es el que se ha venido utilizando por la comunidad científica internacional, de acuerdo con los criterios establecidos por la Organización de las Naciones Unidas para la Educación, la Ciencia y la Cultura (UNESCO), la cual acordó definir como paisaje cultural una obra conjugada del hombre y la naturaleza, que puede ser, por ejemplo, un jardín, un parque, un paisaje natural o urbano, que ha sido marcado por algún hecho histórico, artístico o cultural.

Por tanto, los aspectos que se consideran en un estudio de paisajes culturales urbanos de los centros históricos, son complejos y se manifiestan de diferentes modos. Entre estas expresiones están (Zárate, 2007):

La toponimia y la identidad. La toponimia es una marca cultural y expresa la efectiva apropiación del espacio por un grupo cultural; articula lenguaje, política territorial e identidad.

La creación y la fundación de formas simbólicas. Por medio de las formas simbólicas, la ciudad expresa una cultura o realiza su transformación cultural tanto en el espacio como en el tiempo, en su forma, su función y significado; por ejemplo, la centralidad de una catedral en la ciudad medieval se desvanece en la ciudad metropolitana. 
El paisaje urbano y sus significados. Los paisajes urbanos permiten múltiples lecturas, ya que se reciclan y transforman a partir de distintos contextos histórico-culturales que incluyen diferencias sociales, de poder, creencias y valores.

En función de lo anterior, se abordan como elementos básicos para el conocimiento de los paisajes culturales urbanos, los aspectos relacionados con los componentes del paisaje y su evolución histórica, en los rubros de origen del sitio y su soporte físico.

\section{La propuesta metodológica}

A partir de los criterios establecidos por las convenciones internacionales, se elaboró una ficha ${ }^{7}$, a manera de guía metodológica, con los elementos específicos que deben ser considerados para el análisis del paisaje cultural urbano de las ciudades patrimoniales, señalando los paisajes e itinerarios culturales, con el fin de contribuir a su conservación y a instrumentar medidas de prevención ante los peligros que los amenazan. Los principales apartados que integran esta ficha se resumen de la siguiente forma: A. justificación,

7 La ficha referida fue propuesta por el Dr. Manuel Antonio Zárate Martín de la Universidad Nacional de Educación a Distancia de Madrid, España (UNED), en el proyecto Dinámicas Sociales de los Paisajes Culturales Urbanos y Estrategias para su Conservación a través de casos en México y España. delimitación y definición de la unidad de paisaje objeto de análisis; $\mathbf{B}$. componentes del paisaje y evolución histórica; C. dinámicas sociales y D. amenazas y oportunidades. (Figura 1, anexo 1).

Para el punto A, se deben tomar en cuenta los siguientes valores:

Culturales y estéticos, ya sean de índole natural o medioambiental.

Patrimoniales, aquellos apreciados por su historia y carácter artístico, con un contenido simbólico, identitario, espiritual, religioso o mitológico.

Además de considerar que cualquier valor pudiera perfilarse como un elemento productivo, por su capacidad para actuar como recurso económico a lo largo del tiempo, así como conocer las funciones actuales de estos elementos del paisaje y determinar una propuesta para el futuro.

La escala es importante porque permite, mediante una panorámica urbana, ver el paisaje natural que la rodea y el paisaje cultural que han creado sus habitantes a lo largo del tiempo, representado por espacios singulares, plazas y fuentes, vías principales, conjuntos religiosos o monumentales.

Para el punto B, es importante ocuparse de lo siguiente: 


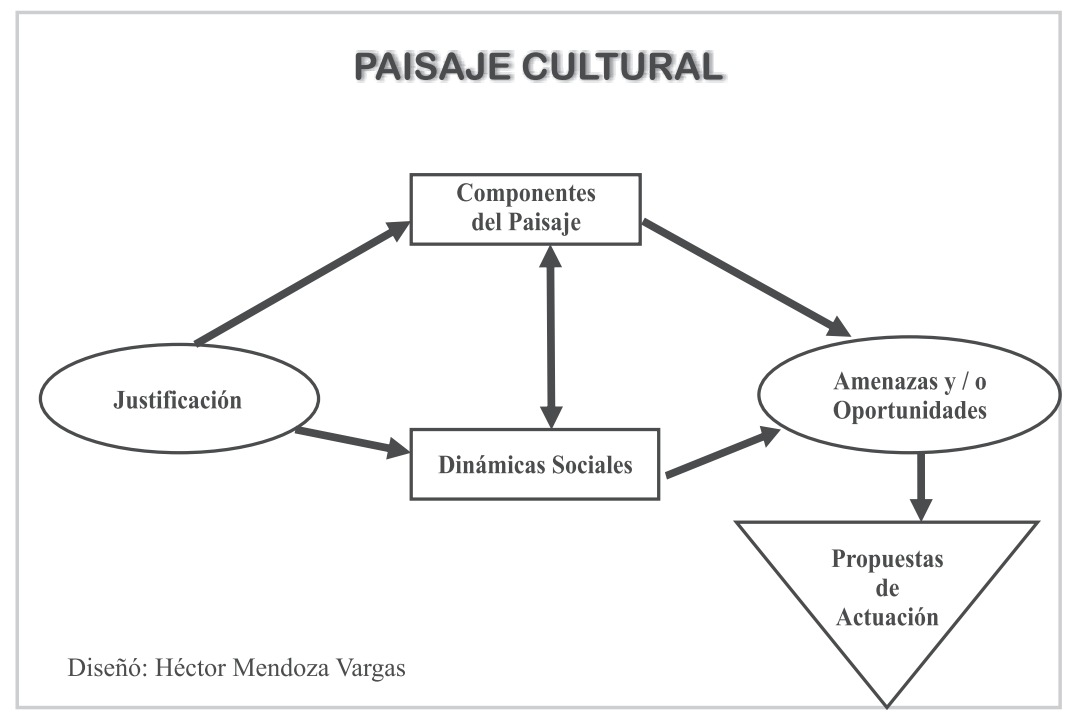

Figura 1. Elementos del paisaje cultural urbano.

Fuente: Seminario Interno (2010). Dinámicas sociales de los paisajes culturales y estrategias para su conservación a través de casos en México y España.

Elaborar la descripción del sitio, por una parte: conocer su relieve, suelos, elementos medioambientales, clima, vegetación, así como su dinámica demográfica social y económica, y, por otra parte, mediante trabajo de archivo, investigar las representaciones plásticas del mismo realizadas a lo largo del tiempo, ya sean gráficas o cartográficas, como planos, grabados, pinturas, fotografías. También es importante localizar en fuentes literarias referidas al lugar, las alusiones al paisaje social construido a lo largo de la historia; estas fuentes pueden ser documentos de escritores de renombre o viajeros históricos. En relación con esto último, será conveniente recurrir a publicaciones turísticas, como guías y folletos antiguos, con el fin de detectar el momento en que los espacios y paisajes analizados se convirtieron en elementos de atracción turística, investigar posibles cambios en ese sentido, desde la preocupación exclusiva por los elementos monumentales, hasta una visión más integral que pueda incluir valores arquitectónicos del conjunto, paisajísticos, sociales o funcionales.

Las dinámicas sociales señaladas en el punto $\mathbf{C}$ se refieren tanto a la situación actual del lugar analizado como a los cambios experimentados en el pasado, relacionadas con aspectos sociales, tales como: estructura poblacional, representaciones cartográficas e informaciones censales, lo más detalladas posible, dependiendo 
de la escala: un paisaje general de la ciudad, una plaza, una vía importante o un espacio público. En este punto interesa mostrar los cambios sociales y su influencia sobre el paisaje, ya que esto es el eje del trabajo y, por lo tanto, la idea transversal que preside todos los elementos analizados.

El sentido de todo lo anterior es detectar lo que señala el punto $\mathbf{D}$, pues estos espacios pueden estar amenazados y ser susceptibles de destrucción, ya sea por las características de su construcción, tipologías arquitectónicas, antigüedad de los edificios, estado de conservación y grado de ocupación, en caso de ser utilizados como vivienda, o bien por el impacto que se produce debido al crecimiento urbano.

Es importante también conocer los planes del gobierno local referentes al tema, para lo cual se requiere saber las normas de protección y ordenación para la zona del planeamiento urbano, desde el general, hasta los planes especiales y ordenanzas municipales específicas, valorando los efectos del planeamiento en la conservación y utilización de los edificios y del espacio circundante.

Las oportunidades mencionadas en este mismo punto se relacionan con el interés y el aprovechamiento turístico, para lo cual resulta primordial obtener imágenes atractivas de la ciudad, conocer las propuestas de intervención sobre ese espacio de promotores urbanos, ya sean públicos o privados, la incidencia sobre el mismo de las políticas turísticas, los acontecimientos o eventos festivos, las prácticas residenciales y de esparcimiento y los acuerdos o conflictos que pudieran surgir al estar en discrepancia con las imágenes mentales de residentes, comerciantes y asociaciones de vecinos sobre el turismo en la zona.

Finalmente, al analizar lo anterior se pretende elaborar una propuesta de actuación, señalando los valores patrimoniales de ese paisaje cultural, relacionados con espacios que permitan la convivencia con fines educativos, estéticos, sociales y culturales. Las recomendaciones deben ser en el sentido de conservar estos valores, pero proponiendo estrategias para el beneficio económico de la sociedad que posee estos bienes y procurando el desarrollo local. Dichas estrategias deberán estar acordes con los criterios de los convenios del Patrimonio Mundial (1992) y del Paisaje (2000), que señalan la importancia de un uso sostenible socialmente y respetuoso con el patrimonio.

\section{El estudio de caso}

Con el fin de concretar un estudio de caso que permita aplicar estos conceptos, se eligió la ciudad de Zaca- 
tecas, en donde los puntos de vista considerados fueron: el origen del emplazamiento como ciudad minera y como frontera cultural en la época colonial, el crecimiento poblacional, la arquitectura colonial y su importancia dentro del sistema de ciudades del virreinato, cuya función fue la explotación minera, lo cual les da una traza singular que se ha denominado de plato roto, debido a que, al expandirse, se adaptaron al terreno montañoso en el que se localiza el mineral (Curiel, 2007, p. 26).

Zacatecas fue un sitio estratégico para los conquistadores españoles que requerían de materias primas (estaño y plomo) para la industria de la guerra emprendida contra los naturales de este país, aunque posteriormente, la búsqueda se centró en la obtención de minerales preciosos como el oro y la plata que fueron localizados en estos sitios.

Actualmente constituye una muestra de la riqueza en valores culturales contenida en sus construcciones de las distintas épocas. Esto es un potencial tesoro de gran valía que, desde el punto de vista geográfico, representa un recurso para el desarrollo económico de sus pobladores, a diferentes escalas espaciales, el cual permitirá, principalmente, el fomento al turismo cultural hacia esta ciudad.

\section{Componentes del paisaje cultu- ral en la ciudad de Zacatecas}

Descripción del sitio en donde se asienta la ciudad de Zacatecas. Las ciudades mineras generalmente se encuentran en las zonas montañosas, ya que es en estos relieves en donde se localizan los minerales. Por eso, estas ciudades se caracterizan por tener una topografía tortuosa, con calles serpenteantes que presentan irregulares declives (Figura 2). Este tipo de localidades, si bien por una parte suelen poseer paisajes naturales atractivos, por otra, su establecimiento representa dificultades para dotar a las viviendas de servicios como agua, drenaje, luz, gas y otros, así como problemas con los transportes, pues sus calles casi siempre son angostas (Taylor, 1954, p. 346-370).

La ciudad de Zacatecas es un ejemplo representativo de este tipo de metrópolis, por estar localizada en una cañada que forma la Sierra de Minas. La meseta en donde se ubica, está formada de sienita, sobre la cual descansan unas capas de esquisto primitivo y de clorito esquistoso, y en los lagos de la parte norte abundan el muriato y el carbonato de sosa, que se usa en la fundición de los muriatos y de los sulfuros de plata (Humboldt, 2004, p. 169-170).

Durante los períodos Jurásico y Cretácico, el mar cubría esta región, por 


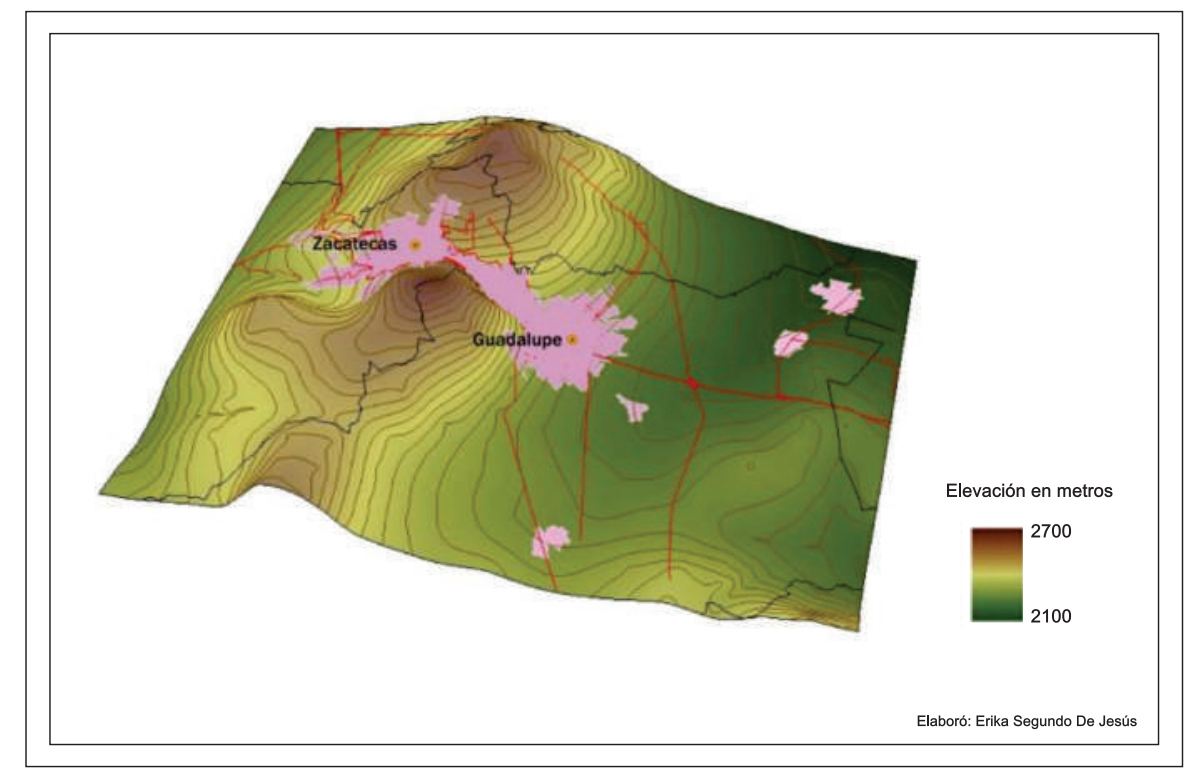

Figura 2. Conjunto de datos vectoriales de la serie topográfica y de recursos naturales, ESC 1: 1000 000. Las curvas topográficas se generaron a partir del Satélite TOPEX.

Fuente: INEGI (2011).

lo que contiene rocas calizas y sedimentarias al noreste. De acuerdo con Rodríguez (1974), se trata de un área donde existe predominio de regolitas derivadas de las rocas verdes de Zacatecas y sedimentos marinos del Triásico; también hay afloramientos de interestratos de rocas volcánicas submarinas y sedimentos, los cuales conforman lomeríos. En estos últimos se observan fallas inversas y estructuras de rocas submarinas. Las lavas son basálticas del período Triásico (Figura 3).

Por ejemplo, el cerro de la Bufa, tan representativo e identitario de la ciudad de Zacatecas, es una formación endógena de roca ígnea que, al que-

dar desprovista por la denudación de la roca sedimentaria que la cubría, permitió el afloramiento del macizo rocoso con una forma tan peculiar que ha dado lugar a interpretaciones diversas en el imaginario de quien lo observa. Así, para algunos, la Bufa es un saurio de sulfato de cobre, su giba llagada por acantilados y cuarteaduras produce la impresión de una mole de escamas..., para otros, tiene la forma de la vejiga de un cerdo, de la hombrera de cierta armadura, o se parece a la capucha del hábito de antiguas cofradías (Hernández, 2005, p. 13). En sus inmediaciones se localizan actualmente el Santuario de la Virgen del Patrocinio, el Museo Toma de Zacatecas, el Observa-

92 Ortíz Alvarez María Inés, Tamayo Pérez Luz María Oralia, Villaseñor Franco Alma 


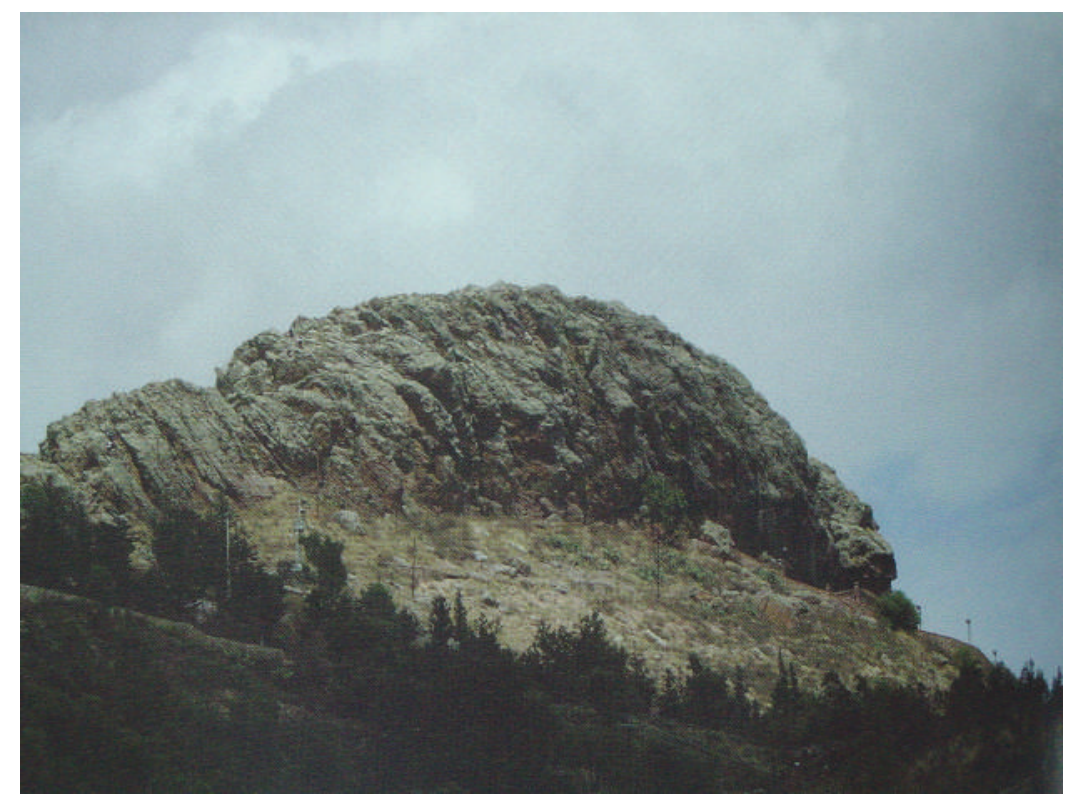

Figura 3. El cerro de la Bufa.

Fuente: Hernández (2005)

torio Meteorológico, el Mausoleo de los Hombres Ilustres ${ }^{8}$ y la Plaza de la Revolución con las esculturas ecuestres en bronce de los principales generales de la División del Norte de la Época Revolucionaria (Felipe Ángeles, Pánfilo Natera y Francisco Villa) ${ }^{9}$ y la estación del teleférico.

8 En este mausoleo se encuentran los restos de las siguientes personas: Francisco Aguilar y Urízar (1867-1948), pianista, compositor y maestro emérito de la UAZ; Genaro Codina Fernández (1852-1901), músico, compositor destacado y autor de la Marcha Zacatecas; Úrsulo García Arizmendi (1882-1937) educador y luchador social por la causa obrera y campesina; Fernando Villalpando Ávila (18441902), músico y compositor zacatecano (Travelbymexico, s.f.).

9 Esto último se debe a que fue principalmente en este cerro desde donde se dirigieron las operaciones militares que dieron lugar a la toma de esta ciudad por los revolucionarios y con esto inició la derrota del gobierno ilegítimo de Victoriano Huerta.

\section{La fundación de la ciudad de Zacatecas y su patrimonio cultural}

Antes de la llegada de los españoles, la región estaba habitada por diversos grupos indígenas, el principal era el de los Zacatecos, quienes cultivaban maíz y cazaban conejos, venados, perdices y otros (Rodríguez, 1977, p. 56-59). Estos indígenas se asentaron en el cerro de la Bufa, y, a la llegada de los conquistadores, les mostraron piedras que contenían plata, lo cual despertó el interés de Juan de Tolosa, quien exploró el terreno y localizó una rica veta. Este descubrimiento originó la reunión de Cristóbal de Oñate, Baltasar Temiño de Bañuelos, Diego de Ibarra y el mismo Tolosa, quienes el 20 de 
enero de 1548 fundaron esta ciudad con el nombre de Zacatecas ${ }^{10}$. A la localización de la primera veta siguieron otras ${ }^{11}$ que ocasionaron el rápido poblamiento de la ciudad por familias españolas. Así, la explotación de la plata fue un elemento fundamental para la fundación y el desarrollo de esta ciudad; con ello, el trabajador de la mina por un lado y el hacendado dueño de la mina, por otro, fueron los principales habitantes de la ciudad durante la época colonial. La dinámica alrededor de la mina contribuyó al establecimiento de diversas haciendas; de las ganaderas se obtenían los animales que eran utilizados para transportar el mineral hacia las de beneficio; de manera similar, las haciendas de campo abastecían a la población de granos y alimentos para su consumo y también les proporcionaban la madera necesaria en esta actividad.

Esto diezmó los bosques de la región y sustituyó el paisaje cubierto de vegetación por un paisaje de cerros desnudos que, por la acción de los procesos erosivos, fue eliminando el sedimento que los cubría.

\footnotetext{
10 Zacatecas proviene del término náhuatl tzacapetal, hierbazal o prado y tepatla, serranía, por lo que Zacatecas significa Serranía en donde abunda el zacate. Establecieron cuatro barrios primitivos para los naturales: Mexicapan, Tlacuitlapan (Tlaxcaltecas), Templo de Jesús (tecuexes), San José de la Montaña (Michoacanos) y Tonalón Chepinque (teonaltecas) (Rodríguez Flores, E., 1977:86-87).

11 La Albarrada de San Benito, San Bernabé y Los Tajos (Rodríguez, 1977, p. 86-88)
}

En 1585, el rey Felipe II, por Cédula Real, le dio el título de Ciudad de Nuestra Señora de los Zacatecas, y tres años después, el mismo monarca la distinguió con el epíteto de muy Noble y Leal Ciudad de Zacatecas, además la honró con su escudo de armas (Figura 4) ${ }^{12}$, privilegio del que gozaron muy pocos pueblos en la Nueva España. Ya para 1748, Villaseñor y Sánchez testificaba que esta ciudad estaba habitada por más de cinco mil familias de españoles, mestizos y mulatos.

Entre los siglos XVI y XVIII, la ciudad se convirtió en el centro desde el cual las diversas órdenes religiosas, principalmente la de los franciscanos, iniciaron la tarea evangelizadora y cultural hacia la porción septentrional del territorio novohispano.

12 Según la Cédula Real original, debe tener la forma de un escudo español. En su único campo predomina una elevación que representa el emblemático cerro de la Bufa, a cuyos pies nace la ciudad en 1546, como producto del descubrimiento de las ricas minas de plata. En la parte más eminente del cerro aparece una cruz de plata, y al centro, una imagen de la Virgen María, por haberse descubierto este cerro y las minas el día en que la Iglesia Católica celebra la fiesta de la Natividad de la Virgen; abajo, el monograma del Felipe II, como testimonio de quien otorgó el escudo de armas a la ciudad. En los dos extremos superiores del escudo flotan el sol y la luna en un cielo de color azul intenso. En la falda del cerro hay cuatro retratos de personas en campo de plata en memoria de Juan de Tolosa, Diego de Ibarra, Baltasar Temiño de Bañuelos y el capitán Cristóbal de Oñate, principales fundadores, mineros y pobladores de Zacatecas; debajo de ellos aparece el lema Labor vincit omnia (el trabajo lo vence todo); y en la orla, cinco manojos de flechas entremetidos con otros cinco arcos, que son las armas que usaban los referidos indios chichimecas (Municipios de México, s.f.). 
Entre las edificaciones que fundaron estas órdenes religiosas y que constituyen parte de la riqueza cultural de Zacatecas, están las siguientes: en el siglo XVI (1576) el templo de San Agustín; en el siglo XVII (1604) el templo de Santo Domingo; en 1610, el convento hospital de San Juan de Dios; en 1616, el de Nuestra Señora de la Merced y el Colegio de la Sagrada Compañía de Jesús. Del siglo XVIII se tienen construcciones como la Parroquia Mayor, dedicada a la Purísima Concepción de Nuestra Señora, que sería llamada Catedral Basílica de Nuestra Señora de los Zacatecas por haberse encontrado el mineral $^{13}$ un 8 de septiembre, fecha en que se celebra dicha advocación, la Natividad de la Virgen María; el Santuario la Bufa, el de San Francisco y el de Nuestra Señora de los Remedios. A una legua (4. $190 \mathrm{~m})$ al oriente de la ciudad de Zacatecas se encuentra el Santuario de Nuestra Señora de Guadalupe, que fue el Colegio de Propaganda FIDE, (de Guadalupe y el Colegio de los Apostólicos Misioneros Franciscanos (Villaseñor y Sánchez, J. A., 2005, p. 555-557). La ciudad estaba gobernada por un corregidor capitán a de guerra, doce regidores y otros. Contaba con una Caja Real en donde se almacenaba la plata extraída de las minas (Figura 4).

13 Juan de Tolosa descubrió la veta de plata (Villaseñor \& Sánchez, 2005, p. 555).
Algunos de los edificios virreinales fueron residencia de personajes notables como el que ocupó el primer periodista de América, Juan Ignacio de Castorena Ursúa y Goyeneche ${ }^{14}$.

Entre las Instituciones construidas entre 1824 y 1825 están la primera imprenta en Zacatecas, la Tesorería General del Estado, la Administración de Rentas de la Capital, el Tribunal Superior de Justicia, el Tribunal de Alzadas de Comercio y el Tribunal de Alzadas de Minería; en 1826, la Primera Escuela Normal de América, en 1827 se construyó el Portal de Rosales, en 1833, en el lugar ocupado por la cárcel, se levantó un teatro que posteriormente se llamó Teatro Calderón, en honor al dramaturgo Fernando Calderón. Durante el Porfiriato se construyeron numerosos templos y edificios en muchas fincas, con influencia francesa, que le añaden elementos de valor cultural al espacio estudiado.

En la época actual se han rehabilitado construcciones arquitectónicas coloniales que hoy albergan museos, entre ellos destacan el de Pedro Coronel, acondicionado en la antigua fortaleza jesuita en la actual Plaza de

\footnotetext{
14 Juan Ignacio de Castorena Ursúa y Goyeneche y de Villareal fue colegial de San Ildefonso, en donde obtuvo el Doctorado en Cánones; fue contemporáneo de Sor Juana Inés de la Cruz, quien le dedicó una décima; fue Inquisidor Ordinario, fundó la Gaceta de México y Noticias de Nueva España, que se considera la primera publicación regularizada (Hamue, R., 2008).
} 


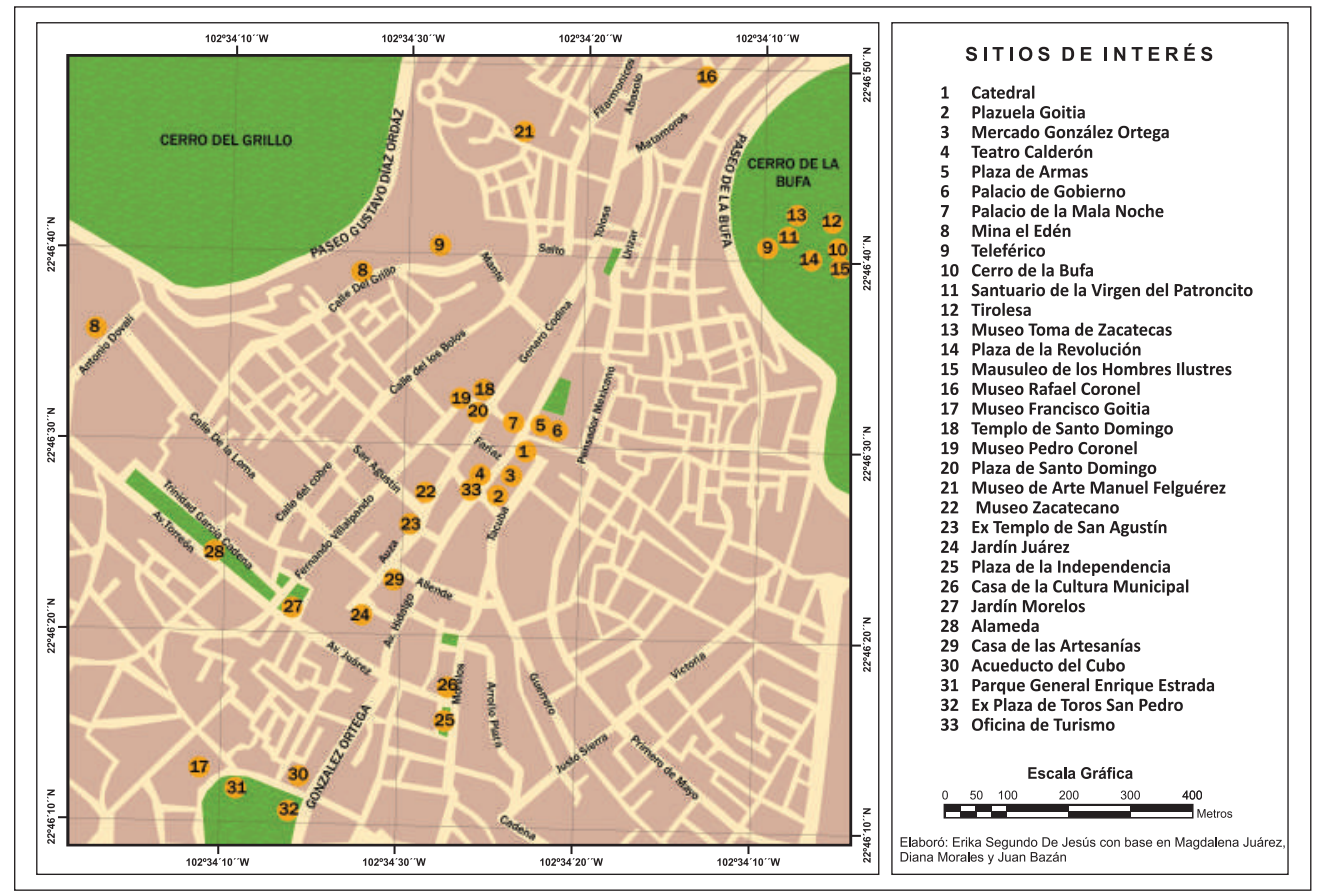

Figura 4. Mapa Urbano de la ciudad de Zacatecas.

Fuente: Romo (2008).

Santo Domingo, el Museo Rafael Coronel, situado en las ruinas del Convento Franciscano, la Casa de Moneda; el Museo Toma de Zacatecas se localiza en la explanada del cerro de la Bufa. Al antiguo mercado se le renombró Mercado Jesús González Ortega y, en el segundo piso de este funcionó un teatro y un centro cultural (González, 2005, p. 13-23).

Para poder rescatar los elementos identitarios con valor patrimonial, es necesario conocer diversos datos relevantes de otras épocas. Durante el siglo XIX destacan los siguientes acontecimientos: el 5 de julio de 1821 se firmó el acta para declarar estado independiente e integrante de la Fe- deración Mexicana al ahora estado de Zacatecas; entró en vigor la Primera Constitución Política del estado; se decretó la abolición de la esclavitud en el estado en 1826 y se fundó la Sociedad Patriótica de Amigos del País. En 1884 llegó el primer tren a la ciudad, se instalaron la energía eléctrica, el teléfono y el telégrafo.

También resaltan los nombres y las obras de personajes importantes del siglo XIX, como Jesús González Ortega, Trinidad García de la Cadena, Víctor Rosales y José María Cos, así como compositores como Fernando Villalpando y Genaro Codina entre otros. 


\section{Valores histórico-simbólicos: la Batalla de Zacatecas}

Esta batalla ${ }^{15}$ fue decisiva para la salida de la presidencia del usurpador

15 El general Urbina debía apoderarse de los cerros de Tierra Negra y Tierra Colorada (Loreto); Villa con sus Dorados atacaría desde otro punto el cerro de Tierra Colorada. Martiniano Servín atacaría el cerro de la Sierpe, Maclovio Herrera debía tomar la Estación del Ferrocarril y los cerros del Grillo y los Clérigos, al sur y sureste de la ciudad. La División del Centro (comandada por Pánfilo Natera) protegería el sur para impedir la llegada de refuerzos federales. Toribio Ortega, situado en Las Pilas, contraatacaría para apoyarlos. La artillería villista apoyaría al agrupamiento comandado por Villa, al de Maclovio Herrera y a otros dos grupos que se encontraban en el corralón de la Mina de La Plata.

Los federales contaban con doce mil soldados comandados por el general Luis Medina Barrón, a cuyas órdenes estaban los generales Benjamín Argumedo, Jacinto Guerrero, Manuel Altamirano, Antonio Rojas, Antonio Olea, José Soberanes y Juan N. Vázquez. Estas tropas estaban situadas en los cerros de La Bufa, Tierra Negra, La Sierpe, El Grillo, Estación de Ferrocarril, Los Clérigos, Crestón Chino, Guadalupe y Refugio.

El ataque se inició a las diez de la mañana de ese 23 de junio; la batalla fue difícil y costosa en pérdidas humanas de los dos bandos. Los villistas se fueron apoderando de las posiciones ocupadas por los federales hasta llegar al centro mismo de la ciudad, en donde fueron bombardeados los edificios del Banco de Zacatecas y la Jefatura de Armas. Además los militares huertistas, como venganza, habían explotado una manzana completa con sus habitantes. Al salir de la ciudad, los Federales, desorganizados, huyeron en distintas direcciones, seguidos por los villistas que los exterminaban con regocijo salvaje y brutal, y la muerte ocupó la ciudad junto con los vencedores revolucionarios que, agotados por el infierno vivido y al amparo de la noche, se tiraron a dormir en la Plaza Independencia, junto a los cadáveres de algunos de los vencidos. Al amanecer, los cuadros macabros que los rodeaban se extendían por casi toda la ciudad; mujeres y niños pagaron también con sus vidas los horrores de la sangrienta batalla. La revolución, con este tipo de guerras fratricidas, fue injusta para algunos, como lo expresó Felipe Ángeles quien reflexionó lo siguiente al ver los cadáveres de sus enemigos:

$Y$ pensar, que la mayor parte de los muertos fueron cogidos de leva por ser enemigos de Huerta y por ende amigos nuestros. Y pensar que algunos de ellos eran mis amigos, a quienes la inercia del rebaño mantuvo del lado de la injusticia... (Instituto Nacional de Estudios Históricos de la Revolución Mexicana, INEHRM 1985, p. 1-47)
Victoriano Huerta, aunque la lucha revolucionaria continuó por otros siete años; aún así, el enfrentamiento que tuvo lugar en la ciudad que le dio su nombre, la marcó de tal forma que todavía se encuentran elementos que la recuerdan de manera permanente y por los cuales este hecho constituye un valor identitario para la misma.

Se llevó a cabo el 23 de junio de 1914. Francisco Villa, que había logrado importantes triunfos en el norte del país, consideraba que tomar Zacatecas era un objetivo elemental para llegar a la ciudad de México, ocupada por el traidor Victoriano Huerta. Zacatecas estaba defendida por las tropas federales de Huerta y tanto Francisco Villa como Venustiano Carranza sabían la importancia de dominar a esta ciudad. Carranza, jefe del Ejército Constitucionalista, ordenó a Villa enviar refuerzos a Pánfilo Natera, general revolucionario a quien Carranza había enviado sobre Zacatecas. Francisco Villa, que deseaba obtener para su División del Norte el triunfo, desobedeció las órdenes de Carranza y se preparó para un ataque bien planeado y definitivo días después. Natera, sin el auxilio de Villa, fue repelido por las tropas federales, después de lo cual Villa comenzó su marcha sobre esta ciudad. Para el amanecer del 23 de junio ya toda la División de Norte -cerca de treinta mil hombres- al mando de Villa y asesorado por Felipe Ángeles, se 
encontraba alrededor de esta ciudad; su plan de ataque fue tomar los cerros que la rodean, bajar hacia la ciudad y ocuparla, dada su condición de ciudad minera, el cerro de la Bufa fue el punto con la mejor ubicación para la dirección de la batalla.

En memoria de esta gran ofensiva, desde el cerro de la Bufa, donde se encuentra el Museo Toma de Zacatecas, las estatuas ecuestres de Francisco Villa, Felipe Ángeles y Pánfilo Natera observan la ciudad y se erigen al mismo tiempo en parte del paisaje como sus guardianes simbólicos.

\section{Elementos de advertencia para la conservación del paisaje cultural urbano}

Uno de los aspectos por considerar dentro del estudio de los paisajes culturales urbanos es el crecimiento poblacional que constituye, al mismo tiempo, una amenaza por la demanda creciente del espacio urbano y de los recursos básicos como el agua y la vivienda, así como de los servicios tanto para la población local como para la que realiza actividades turísticas; estos últimos representan una oportunidad para la economía de la población local, que no debe perder de vista la conservación de la riqueza patrimonial del paisaje como parte de sus valores identitarios.
La ciudad de Zacatecas ha tenido un notable crecimiento poblacional ( $\mathrm{Fi}$ gura 5) y espacial (Figura 6). Su población aumentó de 32. 866 habitantes en 1900 a 122.889 en 2005, aun cuando en el periodo revolucionario de 1910 a 1921, el descenso de la población fue muy significativo, ya que bajó más de $40 \%$ al pasar de 25.900 a 15.462 personas.

A partir de 1921, la población inicia una lenta recuperación, como se muestra en la curva de crecimiento, en la que se advierten dos etapas, una lenta entre 1921 y 1950 y una posterior con mayor dinamismo. Este importante crecimiento debe ser considerado dentro de las políticas gubernamentales, ya que puede ser una amenaza potencial que afecte el patrimonio cultural.

El crecimiento demográfico se ha manifestado de manera significativa en los últimos 35 años, registrando tasas de crecimiento que van del $4.8 \%$ en el periodo 1970-1980, al $0.76 \%$ en el periodo 2000-2005; sin embargo, aunque la tendencia porcentual es a disminuir el ritmo de crecimiento, los números absolutos siguen en aumento. Cabe señalar que, a partir de 1970 , se conformó la zona metropolitana de Zacatecas, al conurbarse el municipio de Zacatecas con el de Guadalupe, el cual presentó indicadores de crecimiento más altos aún que la propia 


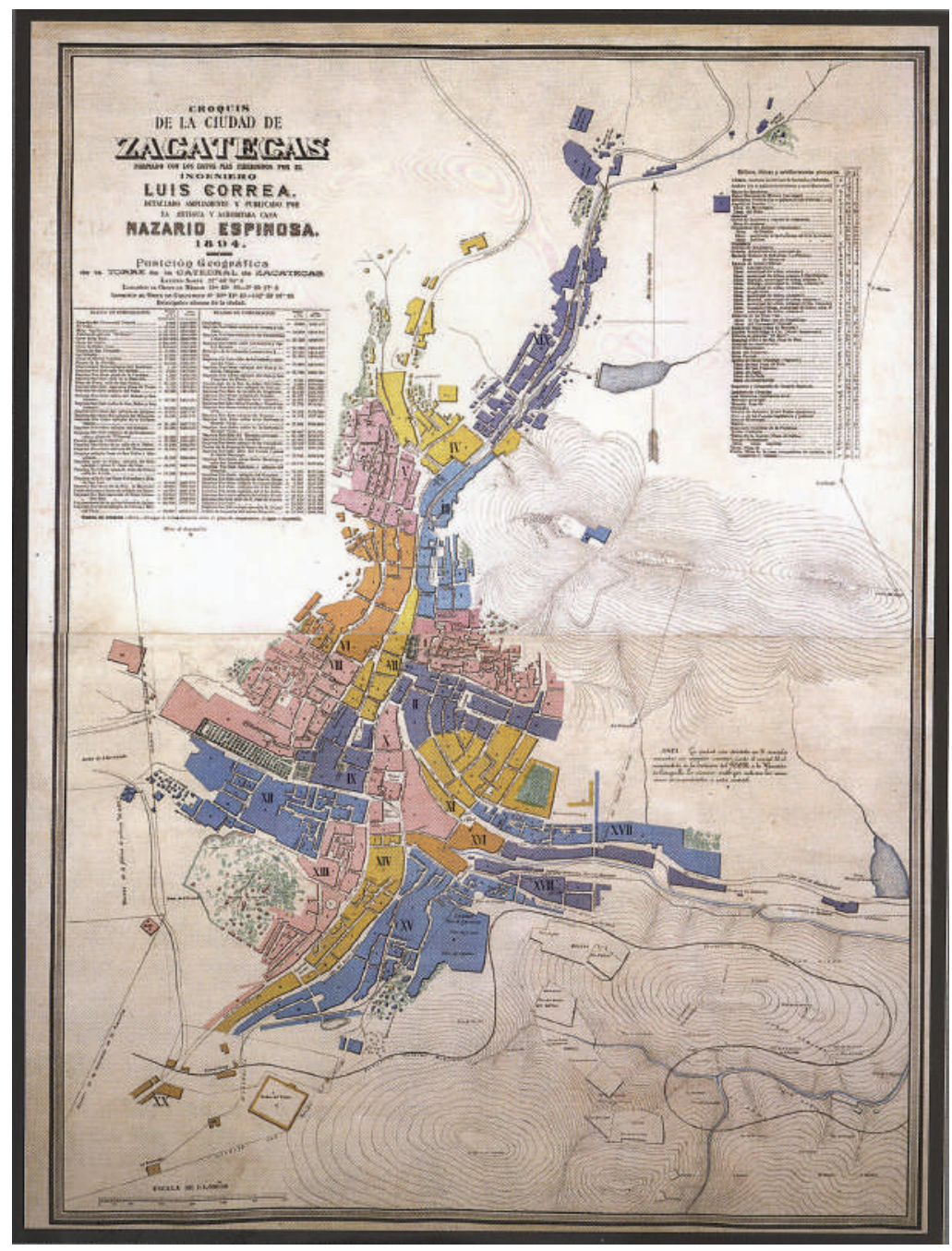

Figura 5. Croquis de la Ciudad de Zacatecas de 1894 de Luis Correa.

Fuente: Archivo Histórico del Estado de Zacatecas.

ciudad (6.7 \% para el primer periodo y $2.6 \%$ para el segundo).

El crecimiento espacial y poblacional constituye una amenaza para el entorno natural, tanto de la ciudad de Zacatecas como de la ahora conurbada población de Guadalupe, ya que, aunque el crecimiento habitacional se ha cargado hacia esta última, la invasión de los cerros entre las dos localidades no es descartable en un futuro, con lo cual terminaría la visión del entorno físico que actualmente es patrimonio y recurso paisajístico natural de la ciudad (Figura 7). 


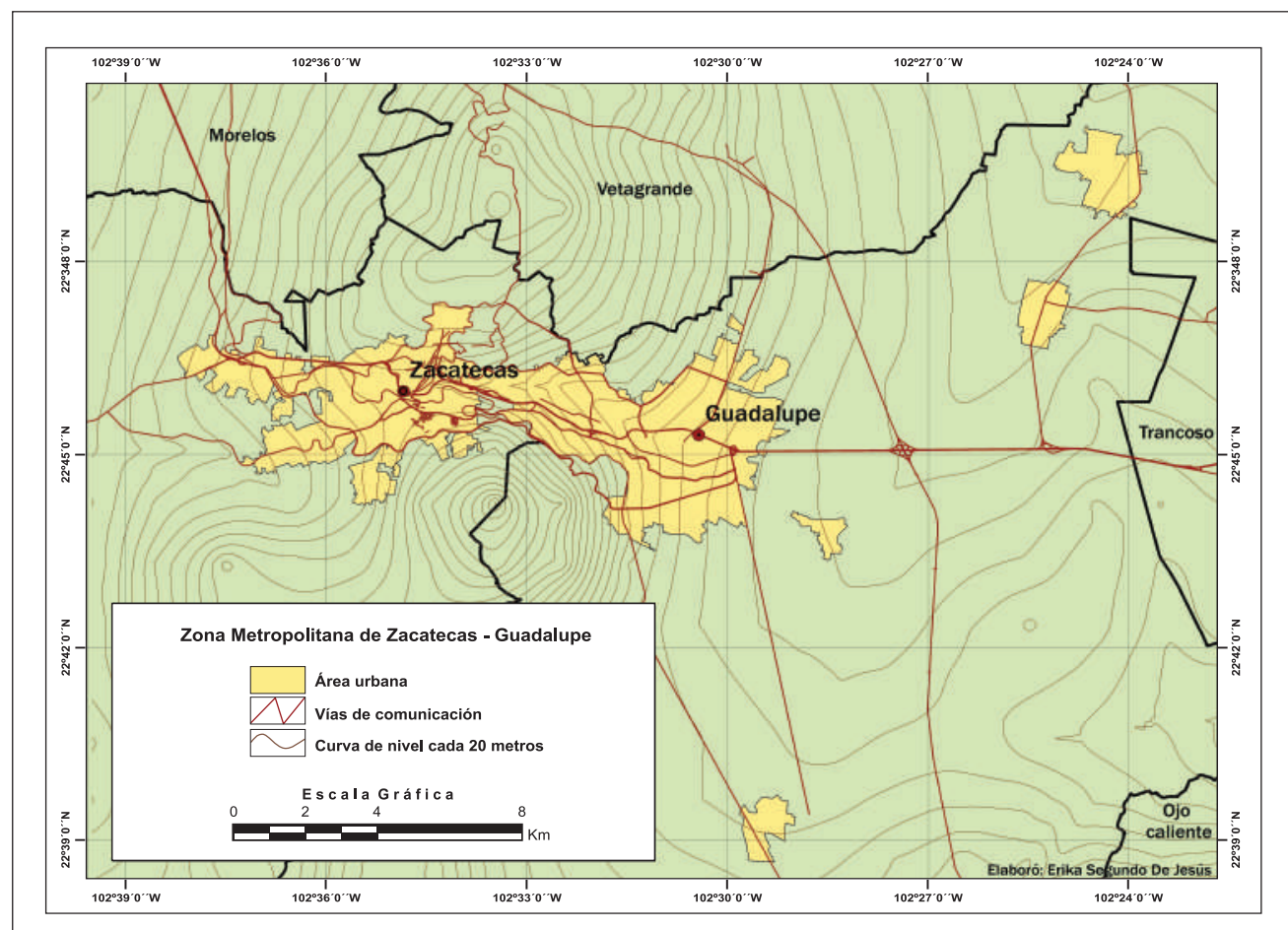

Figura 6. Mapa urbano de la ciudad de Zacatecas. Conjunto de datos vectoriales de la serie topográfica y de recursos naturales, ESC 1: 1000 000. Las curvas topográficas se generaron a partir del Satélite TOPEX.

Fuente: Con base en INEGI (2011).

En el país se tienen numerosos ejemplos $^{16}$ de la ocupación, con viviendas, de los cerros circundantes, sin considerar el gran riesgo que esto implica por posibles deslaves. En ocasiones se expiden permisos, a pesar de conocer el peligro que correrá la población que se asiente en esos sitios. En el caso de estudio, la pérdida sería doble, ya que, además de la población afectada, se dañarían los sitios emblemáticos que por su valor histórico e identitario, son patrimonio de esta ciudad. Para corroborar lo

16 Zacatecas, Taxco, Guanajuato, Ciudad de México entre otras. anterior se incluyen dos representaciones gráficas del paisaje urbano de la ciudad de Zacatecas en dos diferentes momentos históricos, 1839 y 2003, en las que se observa el gran crecimiento espacial de la ciudad (Figura 8).

\section{Conclusiones}

El paisaje se ha convertido en un tema de interés para la valoración patrimonial de la ciudad. Por el dinamismo histórico y por su diversidad cultural, los paisajes conforman la biografía 


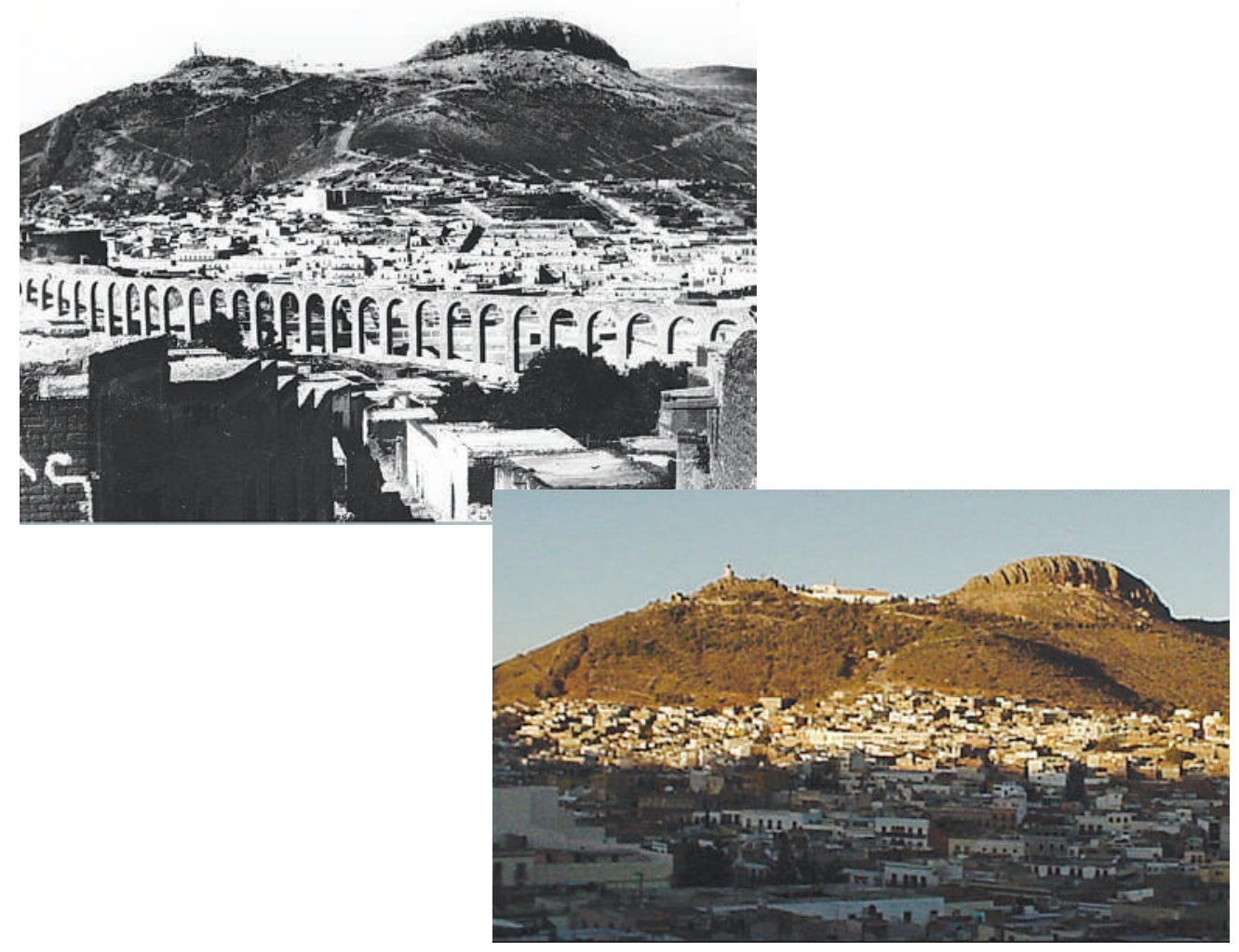

Figura 7. Cerro de La Bufa en dos momentos históricos.

Fuente: Archivo Histórico del Estado de Zacatecas.

de un territorio, y generan con ello la necesidad de una caracterización, catalogación, valoración y conservación de estos, de tal manera que son la base para la sustentabilidad de la misma.

Por otra parte, la expansión urbana se constituye en una amenaza para el patrimonio cultural de esos lugares; ante la demanda creciente o artificial de la vivienda, se especula y se ocupan terrenos que anteriormente eran espacios no urbanos ni urbanizables.
Para reglamentar esto, debe haber una legislación congruente a diferentes escalas gubernamentales, que contemple la preservación de espacios que forman parte de los paisajes de los centros urbanos. Lo anterior debe ser considerado debido a que el paisaje, además de ser un patrimonio, es un recurso económico potencial para fomentar, principalmente, el turismo cultural.

Hacia mediados del siglo XX, se inició el rescate y la preservación de la 


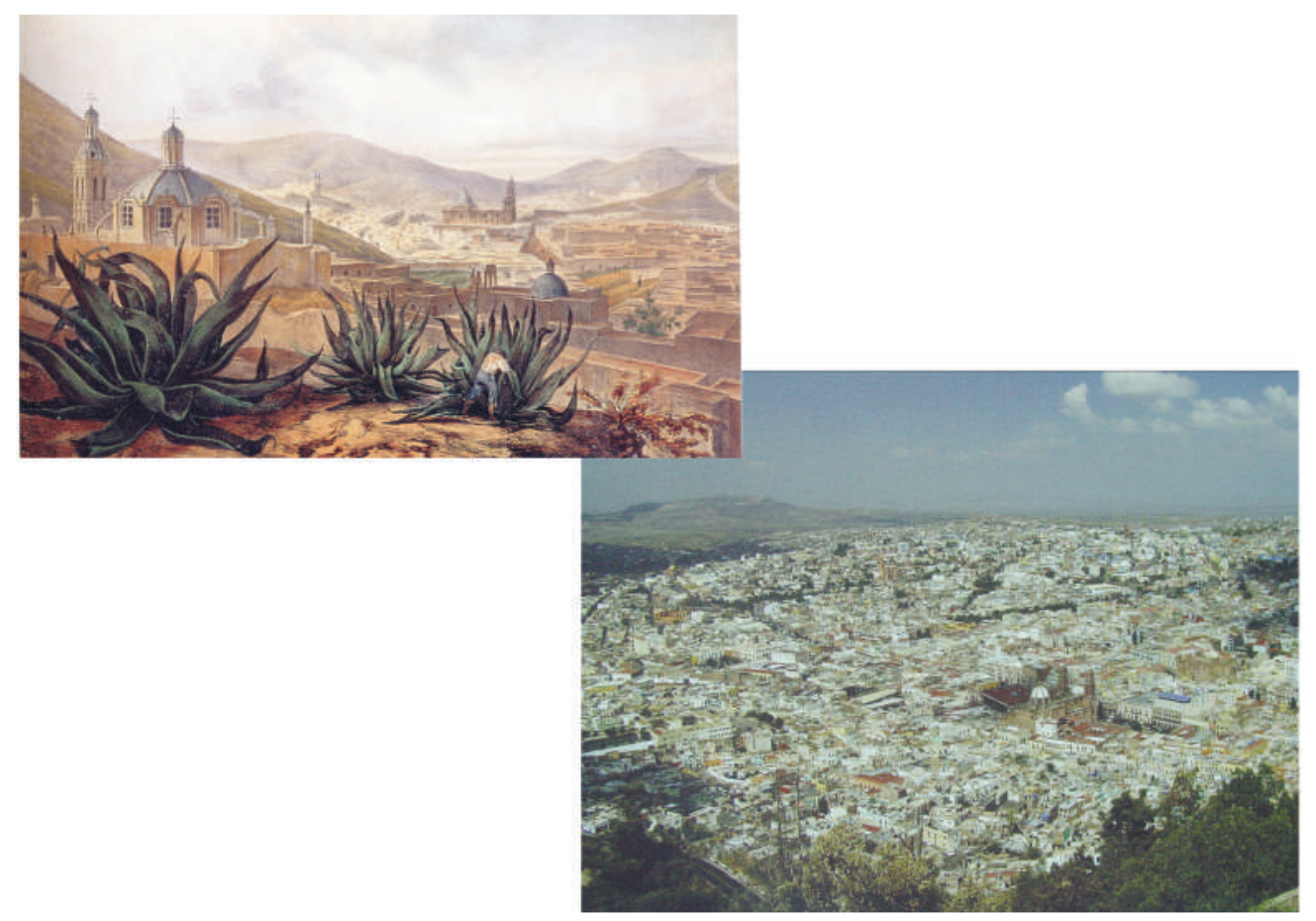

Figura 8. Representaciones espaciales del paisaje urbano de la Ciudad de Zacatecas en dos diferentes momentos históricos. Foto superior: vista de la ciudad en 1839, de Carlos Nevel. Foto inferior: vista panorámica de la ciudad de Zacatecas.

Fuente: Consejo Estatal de Turismo de Zacatecas, en: Zacatecas Camino Real de la Plata, 2003.

fisonomía arquitectónica de la ciudad, y en diciembre de 1993, la Comisión de Patrimonio Mundial de la UNESCO, inscribió en su catálogo de Patrimonio Cultural de la Humanidad, el Centro Histórico de Zacatecas.

Este es un hecho importante para continuar con la restauración de monumentos y la conservación de la fisonomía de la ciudad, pero no debe ignorarse la riqueza paisajística natural que posee, ni las amenazas que se ciernen sobre la misma. Si no se atiende su preservación, se podría perder una parte importante de la esencia misma de esta ciudad.

Con este trabajo se espera contribuir a la valoración de la grandeza cultural que la ciudad de Zacatecas posee, la cual debe considerarse como veta de riqueza en el conocimiento geográfico, por sus monumentos históricos, artísticos y simbólicos valiosos de diferentes épocas, que han impreso en ella huellas muy significativas, además de contar con un paisaje natural que es a la vez identitario. Ha 
sido también cuna de hombres notables tanto para la historia nacional como internacional.

Por tanto, a partir de la metodología propuesta se puede concluir que esta ciudad, en cuanto a sus valores culturales y estéticos (punto A), posee edificios coloniales de gran belleza arquitectónica, además de otros posteriores que, por los materiales con los que están construidos, tienen características únicas de gran belleza. La ciudad posee también elementos de patrimonio intangible que le aumentan su valor, es el caso de las fiestas religiosas y conmemoraciones de los hechos históricos que influyeron en la historia nacional.

En cuanto a lo señalado en el punto $\mathrm{B}$, se destaca el valor del sitio en sí, de su ubicación física y su relieve que le da características estéticas singulares y que han perdurado en el tiempo, como se aprecia en las pinturas que lo muestran.

Respecto a la situación actual (punto C), es conveniente tomar en cuenta el crecimiento poblacional que ha invadido las laderas de los cerros circundantes y que, hasta cierto punto, puede ser una amenaza para la conservación del paisaje natural, pues, esto le restaría valor por el aspecto de la sustentabilidad y porque se perdería parte de su riqueza paisajística. En último término, se recomienda proponer políticas públicas que involucren a la población, que la concienticen sobre los valores patrimoniales que poseen en conjunto; además integrar, con dichos habitantes, convenios de colaboración para que obtengan un beneficio económico al mostrar a los turistas la riqueza de la ciudad, procurando su conservación y evitando su deterioro.

Los habitantes deben percibirse como orgullosos poseedores de dicha ciudad, de la riqueza singular que contiene, de las oportunidades de convivencia que les ofrece y de su significado para la historia nacional, como un bien común a mayor escala; por tanto, el habitarla incluye su cuidado y conservación, así como el beneficio relacionado con la derrama económica que dejan sus visitantes. Mediante este estudio de caso se expone un planteamiento de análisis metodológico que puede ser aplicable a diversos paisajes culturales urbanos y al entorno físico que los rodea.

\section{Reconocimientos}

Las autoras agradecen a María Elena Cea Herrera, por el apoyo en la revisión de la redacción y la corrección de estilo del manuscrito original y a Érika Segundo De Jesús, por la elaboración de la cartografía e imágenes del documento. 


\section{Referencias}

Consejo Nacional para la Cultura y las Artes (2007). Programa Nacional de Cultura 20072012. México: Conaculta.

Curiel, D. F. (Ed.) (2007). Taxco: la perspectiva urbana. (1 ed.). México: Universidad Nacional Autónoma de México. Coordinación de Humanidades. Divulgación de la Humanidades y de las Ciencias Sociales. Programa Universitario de Estudios de la Ciudad.

Gobierno de los Estados Unidos Mexicanos, Presidencia de la República. (2007). Plan Nacional de Desarrollo 2007-2012. México: Poder Ejecutivo Federal.

González, R. M. (2005). Breve historia de Zacatecas. En Artes de México: Zacatecas (34), (pp. 14-23). México: Artes de México y del Mundo.

Hamue, R. (2008). Juan Ignacio Castorena. México: Sistema Nacional e-México. Recuperado de http:// www.e-mexico.gob.mx/wb2/eMex/eMex_Juan_Ignacio_Castorena

Hernández, F. (2005). Los ciegos miradores de La Bufa. Artes de México: Zacatecas, (34), (pp.12-13). México: Artes de México y del Mundo.

Humboldt, A. (2004). Ensayo político sobre el Reino de la Nueva España. México: Porrúa.

INEGI (s.f.). Marco Geoestadístico Nacional. Archivo Histórico de Localidades. Recuperado de http://www.inegi.org.mx/geo/contenidos/geoestadistica/consulta_localidades.aspx

Instituto Nacional de Estadística Geografía e Informática. (s.f.). Zacatecas. México: s.n.

Instituto Nacional de Estudios Históricos de la Revolución Mexicana -INEHRM- (1985). Toma de Zacatecas. Serie de cuadernos conmemorativos, Comisión Nacional para las celebraciones del 175 aniversario de la Independencia Nacional y 75 aniversario de la Revolución mexicana, número 30. México: Talleres Gráficos de la Nación.

Juárez, M., Morales, D. \& Bazan J. (2008). El centro en un vistazo. En Zacatecas, tres ciudades coloniales con estilo propio, Guía México Desconocido. México: Impresiones Aéreas.

Mapserver (s.f.). Mapa urbano de la ciudad de Taxco. Recuperado de http://mapserver.inegi. gob.mx/geografia/espanol/estados/gro/imgs12/p2t_gteg.pdf

Municipios de México. (s.f.). Enciclopedia de los municipios y delegaciones de México. Recuperado de http://sanjoaquinqro.gob.mx/work/templates/enciclo/EMM32zacatecas/ municipios/32056a.html

Rodríguez, F. E. (1977). Compendio histórico de Zacatecas. México: Editorial de Magisterio Benito Juárez, Sindicato Nacional de Trabajadores de la Educación,

Rodríguez, T. R. (1974). Libreto guía de la excursión geológica Zacatecas, Zacatecas a Guanajuato, Guanajuato. En III Convención Geológica Nacional. Programa General. México.

Romo L. (2008). Zacatecas en tres destinos. En Zacatecas, tres ciudades coloniales con estilo propio, Guía México Desconocido. México: Impresiones Aéreas. 
Taylor, G. (1954). Geografía urbana. Un estudio de emplazamiento, evolución, forma y clasificación de pueblos, villas y ciudades. Barcelona, España: Omega.

Topex (s.f.). Mapa urbano de la ciudad de Zacatecas. Recuperado de http://topex.ucsd.edu/ cgi-bin/get_data.cgi/

http://mapserver.inegi.gob.mx/data/inf $1 \mathrm{~m} / ? \mathrm{c}=720$

Travelbymexico (s.f.). Cerro de La Bufa. Recuperado de http://www.travelbymexico.com/ blog/741-cerro-de-la-bufa-un-atractivo-natural/

Varios Autores. (2003). Zacatecas Camino Real de La Plata. México: Grupo Imperial Corporativo S.A. de C.V. Coordinación Editorial Fernández Cueto Editores.

Villaseñor y Sánchez, J. A. (2005). Theatro Americano. México: Universidad Nacional Autónoma de México.

Zárate, M. A. (2007). Documentos de trabajo del proyecto Dinámicas sociales de los paisajes culturales urbanos y estrategias para su conservación a través de casos en México y España. Madrid, España: Universidad Nacional a Distancia. 
Recepción: 20 de noviembre de 2012

Evaluación: 12 de septiembre de 2013

Aprobación: 08 de noviembre de 2013 